\title{
APROVEITAMENTO DO LODO TÊXTIL NA PRODUÇÃO DE BRIQUETES PARA GERAÇÃO DE ENERGIA TÉRMICA
}

\author{
Adenirson Draeger ${ }^{1}$, Vander Kaufmann², Edson Alves de Lima ${ }^{3}$, Mateus \\ Nascimento Vieira de Melo ${ }^{4}$ e Joel Dias da Silva ${ }^{5}$
}

\begin{abstract}
Resumo: O desenvolvimento de técnicas para valorização de resíduos é uma necessidade para diminuir o uso das matérias primas e a degradação ambiental. A utilização de lodo têxtil na produção de briquetes para geração de energia é uma alternativa. Assim, foram produzidos briquetes com quatro proporções de lodo biológico ou lodo físico-químico (0,33, 66 e 100\%) misturados com serragem de Pinus, em duas temperaturas $\left(90\right.$ e $\left.130^{\circ} \mathrm{C}\right)$. O lodo biológico apresentou poder calorífico superior (PCS) de 17,07 MJ. $\mathrm{kg}^{-1}$, valor considerado viável para a queima e geração de energia térmica, já o lodo físico-químico apresentou PCS de 3,4 MJ. $\mathrm{kg}^{-1}$, inviável para esse fim. Os briquetes produzidos com lodo biológico apresentaram resultados favoráveis ao uso

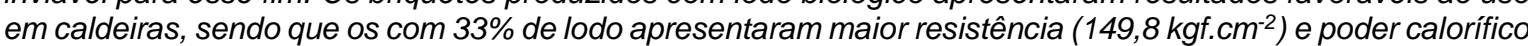
superior (PCS) $\left(18,89 \mathrm{MJ}_{\mathrm{kg}}{ }^{-1}\right)$. As cinzas resultantes da queima dos briquetes ficaram abaixo do limite estabelecido pela norma NBR 10.004 (ABNT, 2004), quanto aos parâmetros inorgânicos.
\end{abstract}

Palavras-chave: Lodo têxtil; valorização de resíduos; energia térmica.

\section{Introdução}

A redução da geração de resíduos e seu melhor aproveitamento são essenciais para diminuir o uso de matérias-primas não renováveis. Em se tratando de recuperação energética é ainda mais importante. A indústria têxtil gera grande quantidade de resíduos sólidos, principalmente, lodo físicoquímico e biológico resultantes do tratamento de efluentes (NUNES et al., 2018). Estes lodos têxteis, em sua maioria, ainda são depositados em aterros sanitários industriais, apesar do seu potencial de aproveitamento no setor energético (VIEIRA et al., 2011; FEAM, 2012; VIKOVÁ et al., 2017). Uma das formas de se aproveitar este lodo é o aproveitamento energético em caldeira de biomassas (BASTIAN; ROCCO, 2009; AVELAR et al., 2016). A queima com recuperação de energia, denominada "waste to energy", temse mostrado promissora no aproveitamento dos resíduos orgânicos (PSOMOPOULOS; BOURKA; THEMELIS, 2009).

No Brasil ainda não é uma prática comum o uso de lodos em caldeiras de geração de energia devido à falta de conhecimento dos efeitos positivos e negativos. O uso da biomassa originária de lodos em processos de combustão tem grande vantagem devido à redução do uso de combustíveis fósseis, além de reduzir significativamente o volume dos resíduos. Poucos trabalhos aparentam trazer novas informações sobre uso do potencial energético do lodo (ROSA; CHERNICHARO; MELO, 2015).

A mistura do lodo com biomassa vegetal, como a serragem de Pinus, pode ser uma alternativa de aproveitamento para a queima em caldeiras. A compactação de resíduos lignocelulósicos pode ser feita através de prensas mecânicas, resultando em um produto com massa específica entre 1.000 e $1.200 \mathrm{~kg} \mathrm{~m}^{-3}$. A pressão ideal para a compactação é de $1.200 \mathrm{kgf} . \mathrm{cm}^{-2}$. A umidade dos resíduos deve estar entre 8 e 15\%, uma vez que, o excesso de umidade poderá causar explosões devido à formação de vapor no interior dos briquetes (GONÇALVES; SARTORI; LEAO, 2009).

A determinação da composição química elementar quantifica os elementos presentes nos materiais combustíveis. Dentre

${ }^{1}$ E-mail:adenirson.draaeger@edu.sc.senai.br

FURB - Universidade Regional de Blumenau. PPGEA - Programa de Pós-Graduação em Engenharia Ambiental. CAMPUS II - Complexo Tecnológico. Rua São Paulo, 3250 - Itoupava Seca CEP 89.030-000 - BLUMENAU - SC, Brasil

${ }^{2}$ E-mail:vanderkaufmann@gmail.com

${ }^{3}$ E-mail:Edson.lima@embrapa.br

${ }^{4}$ E-mail:mateusnvm@gmail.com

${ }^{5}$ E-mail: dias_joel@hotmail.com 


\section{REA - Revista de estudos ambientais (Online) v.23, n. 1, p.46-56, jan./jun. 2021}

eles, o carbono e o hidrogênio, são os principais elementos para a geração de energia; o enxofre também libera energia, porém, causa problemas de corrosão nas caldeiras e gases poluentes $\left(\mathrm{SO}_{\mathrm{x}}\right)$. O oxigênio e o nitrogênio não fornecem energia, e contribuem negativamente para a geração nos processos de combustão (BORGES; SELLIN; MEDEIROS, 2008).

A compactação de resíduos, conhecida como briquetagem, é uma alternativa bastante atrativa, pois além do resíduo utilizado produzir energia, contribui na minimização dos impactos ambientais decorrentes de seu descarte em aterros sanitários. Outras vantagens da briquetagem são a redução da possibilidade de combustão espontânea e da biodegradação dos resíduos, aumento da densidade energética do resíduo, diminuição do seu volume e redução dos custos de transporte e armazenamento (RODRIGUES, 2010; STOLARSKI et al., 2013). A briquetagem e a queima do resíduo, dependendo de sua composição, podem reduzir em até $98 \%$ o volume original do resíduo. Depois da queima, o material restante pode ser encaminhado para aterros sanitários. Desta forma, o processo de incineração exerce um papel importante na redução significativa do volume dos resíduos a serem disposto em aterros, possibilitando maior vida útil dos mesmos (RENOSAM, 2006; AVELAR et al., 2013).

Diante disso, o objetivo foi estudar a possibilidade de misturar lodo têxtil, resíduo de estação de tratamento de efluentes da indústria têxtil, com biomassa vegetal na fabricação de briquetes, com o intuito de promover o aproveitamento do resíduo industrial bem como, gerar energia. Foram testados dois tipos de lodo têxtil, lodo físicoquímico e lodo biológico, e dois tipos de biomassa vegetal, serragem de Eucalipto e serragem de Pinus.

\section{Metodologia}

O trabalho foi realizado no Laboratório do Programa de Pós-graduação em Engenharia Ambiental da Universidade Regional de Blumenau (FURB). Inicialmente foi avaliado o potencial dos lodos e das biomassas vegetais para a geração de energia. Isso foi realizado através de uma caracterização dos materiais. Essa caracterização serviu para escolher apenas um lodo (físico-químico ou biológico) e uma biomassa vegetal (serragem de Eucalipto ou de Pinus), que foram usados, posteriormente, na fabricação dos briquetes. Foram escolhidos os materiais que demonstraram maior potencial energético.

O lodo físico-químico foi fornecido por uma empresa têxtil do ramo de lavanderia de jeans localizada no Município de Brusque, em Santa Catarina. Já o lodo biológico foi fornecido por uma empresa têxtil do ramo de tinturaria localizada no município de Jaraguá do Sul, em Santa Catarina.

Para a caracterização dos lodos e das biomassas vegetais foram determinados à umidade das amostras compostas de acordo com a NBR 8.112 (ABNT, 1986). Em seguida as amostras foram secas em estufa a $60{ }^{\circ} \mathrm{C}$. Após a secagem, as amostras foram moídas em moinho de facas Marconi e passadas em peneira de $0,42 \mathrm{~mm}$ (40 mesh). No material que passou pela peneira determinou-se o poder calorífico superior e estimou-se o poder calorífico inferior $(\mathrm{PCl})$ e poder calorífico útil (PCU); composição química elementar $(\mathrm{C}, \mathrm{H}$, $\mathrm{O}, \mathrm{N}, \mathrm{S}$ ) e análise imediata, composta pelas determinações de materiais voláteis (Mv), carbono fixo (Cf) e cinzas (Cz).

O poder calorífico superior foi determinado em calorímetro IKA C5000, segundo a norma NBR 8.633 (ABNT, 1984). Quanto ao poder calorífico inferior e poder calorífico útil, estes foram estimados pelas equações 1 e 2 , respectivamente.

$$
\mathrm{PCI}=\mathrm{PCS}-[600(9 \mathrm{H} / 100)]
$$

Onde, $\mathrm{PCl}$ é o poder calorífico inferior (MJ.kg$\left.{ }^{1}\right)$, PCS é o poder calorífico superior $\left(\mathrm{MJ}^{\mathrm{kg}}{ }^{-1}\right)$, $\mathrm{H}$ é o teor de hidrogênio na amostra (\%).

$$
\mathrm{PCU}=\mathrm{PCI}(1-\mathrm{W})-(600 \mathrm{~W})
$$

Onde, PCU é o poder calorífico útil (MJ.kg-1), $W$ é a umidade em base úmida, e $\mathrm{PCl}$ é o poder calorifico inferior obtido pela equação 1 .

Os teores de carbono, hidrogênio, nitrogênio e enxofre foram determinados pela combustão seca em analisador Elementar Vario Macro Cube. O teor de oxigênio foi determinado conforme a Equação 3.

$$
\mathrm{O}=100-(\mathrm{C}+\mathrm{H}+\mathrm{N}+\mathrm{S}+\mathrm{Cz})
$$

Onde, $\mathrm{O}, \mathrm{C}, \mathrm{H}, \mathrm{N}, \quad \mathrm{S}$ e $\mathrm{Cz}$ são respectivamente, os teores de oxigênio, carbono, hidrogênio, nitrogênio, enxofre e cinzas. 


\section{REA - Revista de estudos ambientais (Online) v.23, n. 1, p.46-56, jan./jun. 2021}

$A$ análise imediata foi realizada de acordo com a NBR 8.112 (ABNT, 1986). O teor de cinzas foi determinado em mufla marca Sppencer a $700{ }^{\circ} \mathrm{C}$ até massa constante. O teor de voláteis, foi determinado com a amostra já sem umidade e em forno mufla, utilizando-se um cadinho de porcelana com tampa, que permaneceu por $3 \mathrm{~min}$. na porta e mais 7 min. dentro da mufla a $900^{\circ} \mathrm{C}$. $\mathrm{O}$ teor de carbono fixo foi determinado de acordo com a Equação 4.

$$
\mathrm{Cf}=100-(\mathrm{Mv}+\mathrm{Cz})
$$

Onde, Cf é o teor de carbono fixo, Mv é o teor de material volátil, $\mathrm{Cz}$ é o teor de cinzas.

O lodo têxtil escolhido (físico-químico ou biológico), bem como, suas cinzas resultantes da queima em mufla a $700 \stackrel{\circ}{-}$ foram classificados de acordo com a NBR 10.004 (ABNT, 2004) e submetidos ao ensaio de lixiviação, conforme descrito na NBR 10.005 (ABNT, 2004). O ensaio de solubilização não foi realizado, devido ao baixo impacto que o resultado teria na pesquisa.

Para a classificação, as amostras foram coletadas conforme a NBR 10.007 (ABNT, 2004). Para o ensaio de lixiviação, as amostras ficaram em agitação num lixiviador rotativo por $22 \mathrm{~h}$, em seguida, foram filtradas e acidificadas com ácido nítrico e, encaminhadas para laboratório para análise.

Foram determinados na massa bruta e no extrato lixiviado do lodo e das cinzas oriundas de sua queima os metais: As, Ba, $\mathrm{Cd}, \mathrm{Pb}, \mathrm{Cr}, \mathrm{Hg}, \mathrm{Ag}$ e Se, e cloretos, fluoretos e sulfatos, conforme a metodologia descrita no Standard Methods (APHA, 2005).

Para as análises de cloretos e fluoretos foi realizada extração com auxílio de micro-ondas Anton Paar, descrita nos métodos 3051A (EPA, 2007) e 9056A (EPA, 2007) para digestão ácida de lodos assistida por micro-ondas e determinação de ânions inorgânicos por cromatografia iônica.

$\mathrm{Na}$ produção dos briquetes, o lodo escolhido (físico-químico ou biológico), foi depositado sobre uma lona em local coberto por três semanas para redução da umidade, com revolvimento do material uma vez ao dia. Após o tempo de secagem, o lodo foi recolhido e moído em moinho de facas e processado em peneiras de $0,42 \mathrm{~mm}$ (40 mesh). O lodo que passou pela peneira e a serragem da biomassa escolhida (Eucalipto ou Pinus), peneirada na mesma peneira $(0,42$ $\mathrm{mm}$ ), compuseram a mistura para a produção dos briquetes.

A confecção dos briquetes seguiu um delineamento inteiramente casualizado (DIC), em esquema fatorial 2 (temperaturas: $90 \mathrm{e}$ $\left.130{ }^{\circ} \mathrm{C}\right)$ x 4 (proporções de lodo). Assim os tratamentos foram:

$\mathrm{T} 1=0 \%$ de lodo $+100 \%$ de biomassa vegetal; $\mathrm{T} 2=33 \%$ de lodo $+67 \%$ de biomassa vegetal; $\mathrm{T} 3=66 \%$ de lodo $+34 \%$ de biomassa vegetal; $\mathrm{T} 4=100 \%$ de lodo $+0 \%$ de biomassa vegetal.

Os briquetes foram produzidos em briquetadeira de bancada, da marca Lippel, modelo LB-32, com controle da temperatura e pressão do pistão. Neste processo, utilizou-se uma pressão de 1.200 psi em duas temperaturas (90 e $130{ }^{\circ} \mathrm{C}$ ), durante $5 \mathrm{~min}$., seguido de 5 min. de resfriamento.

A perda de massa (PM) foi determinada pela diferença entre a massa da mistura antes da briquetagem e a massa do briquete após a briquetagem, sendo expressa em percentual.

Para a determinação da massa específica aparente dos briquetes foi usado o método estereométrico, ou seja, a relação entre a massa e o volume. A massa foi determinada realizando-se a pesagem dos briquetes com balança semi-analítica, marca Shimadzu, modelo AY220, logo após o resfriamento. Para a determinação do volume dos briquetes, foram realizadas medições dos briquetes em dois pontos opostos no comprimento e, em três pontos no diâmetro, com paquímetro digital Mitutoyo CD 6". A d foi determinada pela equação 5 .

$$
M E=m / v
$$

Onde, ME é a massa específica aparente $\left(\mathrm{g} . \mathrm{cm}^{-3}\right), \mathrm{m}$ é a massa em gramas $(\mathrm{g}), \mathrm{v}$ é o volume $\mathrm{em}^{3}$.

A carga máxima de ruptura (CMR) foi determinada através de uma máquina de teste universal modelo Losenhausen. Assim, a carga máxima de ruptura foi obtida aplicando-se uma força de compressão ao briquete, com velocidade de descida de 3,5 $\mathrm{mm} \cdot \mathrm{min}^{-1}$. O procedimento foi de acordo com a NBR 7.190-Anexo B (ABNT, 1997), já que não existem normas específicas para testes em briquetes. Esta análise foi realizada no Laboratório de Painéis e Energia da Madeira (LAPEM) do Departamento de Engenharia Florestal - Tecnologia da Madeira, da Universidade Federal de Viçosa em ViçosaMG. 


\section{REA - Revista de estudos ambientais (Online) v.23, n. 1, p.46-56, jan./jun. 2021}

A determinação da umidade de equilíbrio higroscópico (UEH) foi realizada submetendo os briquetes a temperatura de 23 ${ }^{\circ} \mathrm{C}$ e umidade relativa de $65{ }^{\circ} \mathrm{C}$, em câmara climática Marconi, até atingir massa constante.

O poder calorífico superior, materiais voláteis, teor de cinzas e carbono fixo, foram determinados da mesma forma que foi feito com o lodo e a biomassa vegetal, descrito anteriormente.

Para as análises de perda de massa, massa específica, carga máxima de ruptura e umidade de equilíbrio higroscópico foram realizadas 5 repetições. Já para poder calorífico superior e análise imediata (Materiais voláteis, Carbono fixo e Cinzas) foram realizadas 3 repetições.

\section{Resultados}

Os lodos (biológico e físico-químico) apresentaram altos teores de umidade, sendo necessária secagem prévia para viabilizar seu uso energético, uma vez que, a alta umidade implica em um baixo poder calorífico útil (Tabela 1).

Tabela 1 - Umidade, poder calorífico superior, poder calorífico inferior e poder calorífico útil , composição química elementar (C, H, N, S e O) e análise imediata ,sendo, material volátil, carbono fixo e cinzas dos lodos têxteis (biológico e físico químico) e da biomassa vegetal (Eucalipto e Pinus)

\begin{tabular}{ccccc}
\hline Parâmetro & $\begin{array}{c}\text { Lodo } \\
\text { biológico }\end{array}$ & $\begin{array}{c}\text { Lodo físico } \\
\text { químico }\end{array}$ & $\begin{array}{c}\text { Serragem de } \\
\text { Eucalipto }\end{array}$ & $\begin{array}{c}\text { Serragem de } \\
\text { Pinus }\end{array}$ \\
\hline Umidade in natura (\%) & $83,28 \pm 0,49$ & $78,90 \pm 0,49$ & $53,04 \pm 2,12$ & $49,70 \pm 1,30$ \\
PCS (MJ.kg-1) & $17,07 \pm 0,15$ & $3,49 \pm 0,07$ & $19,42 \pm 0,21$ & $19,48 \pm 0,36$ \\
PCl (MJ.kg-1) & $16,65 \pm 0,15$ & $3,34 \pm 0,07$ & $19,05 \pm 0,20$ & $19,10 \pm 0,36$ \\
PCU (MJ.kg-1) & $2,28 \pm 0,06$ & $0,23 \pm 0,03$ & $9,28 \pm 0,34$ & $8,85 \pm 0,48$ \\
C (\%) & $48,14 \pm 11$ & $9,35 \pm 0,16$ & $48,17 \pm 0,05$ & $50,06 \pm 0,10$ \\
H (\%) & $7,82 \pm, 0,05$ & $2,86 \pm 0,098$ & $6,82 \pm 0,185$ & $7,06 \pm 0,06$ \\
N (\%) & $5,94 \pm 0,04$ & $0,69 \pm 0,04$ & $0,19 \pm 0,01$ & $0,22 \pm 0,01$ \\
S (\%) & $1,06 \pm 0,06$ & $1,27 \pm 0,02$ & $0,02 \pm 0,00$ & $0,02 \pm 0,00$ \\
O (\%) & $16,15 \pm 0,20$ & $9,62 \pm 0,47$ & $44,22 \pm 0,30$ & $42,40 \pm 0,01$ \\
Mv (\%) & $63,68 \pm 0,26$ & $22,70 \pm 0,37$ & $82,41 \pm 1,21$ & $82,51 \pm 0,91$ \\
Cf (\%) & $14,74 \pm 0,48$ & $1,61 \pm 0,29$ & $17,01 \pm 1,11$ & $17,25 \pm 0,88$ \\
Cz (\%) & $20,89 \pm 0,28$ & $76,21 \pm 0,27$ & $0,58 \pm 0,14$ & $0,25 \pm 0,04$ \\
\hline
\end{tabular}

PCS: poder calorífico superior; $\mathrm{PCl}$ : poder calorífico inferior; $\mathrm{PCU}$ : poder calorífico útil; $\mathrm{C}$ : carbono; $\mathrm{H}$ : hidrogênio; N: nitrogênio; S: enxofre; O: oxigênio; Mv: materiais voláteis; Cf: carbono fixo e Cz: cinzas.

Fonte: Autores (2021)

O lodo biológico apresentou poder calorífico superior de 17,07 MJ.kg-1, sendo próximo aos valores encontrados nas biomassas vegetais, que foram de 19,42 e 19,48 MJ. $\mathrm{kg}^{-1}$ respectivamente, para Eucalipto e Pinus. Borges, Sellin e Medeiros (2008), estudando o poder calorífico de resíduos de madeira, obtiveram 20,10 MJ.kg 1 para lodo sanitário, $19,50{\mathrm{MJ} . \mathrm{kg}^{-1} \text { para lodo }}^{-1}$ de celulose e papel e 17,00 MJ.kg-1 para lodo têxtil. Avelar et al. (2013), para lodo têxtil biológico e resíduo de algodão, chegaram a 21,82 e 17,89 MJ.kg-1, respectivamente. Magdziarz e Wilk (2013) alcançaram 12,24 MJ.kg-1 para lodo sanitário. Pasquini (2014), estudando o potencial energético de vários lodos, encontraram 20,6 MJ.kg-1 para o lodo têxtil. Avelar et al. (2016), para lodo têxtil biológico e resíduo de algodão, obtiveram 21,80 e 17,90 MJ.kg ${ }^{-1}$, respectivamente.
Nunes et al. (2018), analisando os resíduos têxteis, chegaram a $16,80 \mathrm{MJ}^{\mathrm{kg}}{ }^{-1}$. Xie et al. (2018) encontraram 9,87 MJ.kg-1 para lodo de tinta têxtil. Esses valores, exceto o último apresentado, são próximos aos obtidos na presente pesquisa e por isso mostram que os materiais são interessantes para serem utilizados na geração de energia.

O lodo físico-químico apresentou poder calorífico superior $\left(3,4 \mathrm{MJ}^{\mathrm{kg}}{ }^{-1}\right)$ muito baixo em relação aos demais materiais, devido ao teor de umidade desse resíduo $(78,90 \%)$, já que o poder calorífico é inversamente proporcional ao seu teor de umidade no momento da queima (LIMA; ABDALA; WENZEL, 2008). A presença de água representa poder calorífico negativo, pois parte da energia liberada é gasta na vaporização da água e, se o teor de umidade for muito variável, poderá dificultar o processo 
de combustão, havendo necessidade de constantes ajustes no sistema. Outro fator que diminuiu o poder calorífico do lodo físicoquímico é a presença de elevado teor de cinzas (76,21\%). As cinzas são consideradas matéria inerte, a qual não gera calor por não ocorrer combustão.

A partir da Tabela 1 é possível observar ainda que, o lodo biológico apresentou maiores percentuais de $\mathrm{C}, \mathrm{H}, \mathrm{N}$, O e teor de material volátil em relação ao lodo físico-químico. Isso explica o maior poder calorífico superior do lodo biológico em relação ao lodo físico-químico. Os materiais voláteis se desprendem na forma de gases durante a queima e são responsáveis pela maior parte da geração de calor durante a combustão. De acordo com Morais, Nascimente e Melo (2005), os materiais voláteis em biomassa vegetal, como a madeira, variam de 76 a $86 \%$ em base seca. Isso é confirmado pelas análises das serragens de Eucalipto e Pinus no presente trabalho, que foram de 82,41 e $82,51 \%$, respectivamente. Wang et al. (2015), usando palha como fonte de biomassa, obtiveram valores de 69,70\%. Wang et al. (2016), utilizando palha de trigo, chegaram valores de $72,10 \%$. Xie et al. (2018), usando casca de pomelo, alcançaram $68,04 \%$. Portanto, os valores obtidos neste trabalho mostraram-se coerentes e ligeiramente acima se comparado aos demais estudos. Assim sendo, foram escolhidos os materiais lodo biológico e serragem de Pinus para a fabricação dos briquetes, pelo fato de terem apresentado maior potencial para queima e geração de energia.

No entanto, por se tratar de um resíduo industrial, para determinar se a queima para geração de energia é uma alternativa ambientalmente segura e viável é importante conhecer mais um pouco de sua composição química em relação a alguns elementos (Tabela 2).

Observado os dados da Tabela 2 verifica-se, independentemente de ser da massa bruta ou do extrato lixiviado, uma baixa concentração de metais pesados nas amostras de lodo biológico e de cinzas.

Tabela 2 - Valores médios de As, $\mathrm{Ba}, \mathrm{Cd}, \mathrm{Pb}$, Cloretos, $\mathrm{Cr}$, Fluoretos, $\mathrm{Hg}$, Ag, Se e Sulfatos no extrato lixiviado do lodo biológico e das cinzas da queima do lodo

\begin{tabular}{|c|c|c|c|c|c|}
\hline \multirow[b]{2}{*}{ Parâmetro } & \multicolumn{2}{|c|}{ Massa Bruta $\left(\mathrm{mg} \cdot \mathrm{kg}^{-1}\right)$} & \multicolumn{3}{|c|}{ Extrato Lixiviado (mg. $\left.\mathrm{L}^{-1}\right)$} \\
\hline & Lodo & Cinzas do lodo & Lodo & Cinzas do lodo & VMP \\
\hline Arsênio total & $<0,01$ & $<0,01$ & $<0,01$ & $<0,01$ & 1 \\
\hline Bário total & 1,07 & 6,07 & 0,105 & 0,756 & 70 \\
\hline Cádmio total & $<0.002$ & 0,02 & 0,004 & 0,003 & 0,5 \\
\hline Chumbo total & $<0,01$ & $<0,01$ & $<0,01$ & $<0,01$ & 1 \\
\hline Cloretos & 97,48 & 4,49 & n.a & n.a & n.a \\
\hline Cromo total & 0,528 & 2,68 & 0,06 & 0,055 & 5 \\
\hline Fluoretos & 0,06 & n.d & n.a & n.a & 150 \\
\hline Mercúrio total & $<0,001$ & $<0,001$ & $<0,001$ & $<0,001$ & 0,1 \\
\hline Prata total & $<0,03$ & $<0,03$ & $<0,03$ & $<0,03$ & 5 \\
\hline Selênio total & $<0,01$ & $<0,01$ & $<0,01$ & $<0,01$ & 1 \\
\hline Sulfatos & 44,16 & 147,26 & n.a & n.a & n.a \\
\hline
\end{tabular}

Nota-se que a presença de $\mathrm{Ba}$ e $\mathrm{Cr}$ no lodo biológico (massa bruta) tem sua concentração aumentada em aproximadamente cinco e duas vezes, respectivamente, nas cinzas (massa bruta). Isso se explica porque a concentração desses elementos, não voláteis, praticamente não muda, porém, a massa de cinzas diminui significativamente com a queima.

Araújo, Monteiro e Cardoso (2005), estudando a aplicação de composto de lodo têxtil em plântulas de soja e trigo, encontraram valores de 73,9 mg. $\mathrm{kg}^{-1}$ para $\mathrm{Cr}$. Felder e Azzolini (2013), estudando a 


\section{REA - Revista de estudos ambientais (Online) v.23, n. 1, p.46-56, jan./jun. 2021}

viabilidade da queima de lodo originário da indústria de laticínios, encontraram valores de $22 \mathrm{mg} \cdot \mathrm{kg}^{-1}$ para $\mathrm{Cr}$. Valores maiores aos encontrados nesse trabalho. $\mathrm{O} \mathrm{Cr}$ encontrado deve-se provavelmente aos corantes e pigmentos usados na etapa de tingimento. No entanto, sua composição poderá variar de acordo com o processo, e dentro de cada processo, de acordo com o material que se produz.

Quanto aos ânions cloretos e fluoretos, foram encontrados em maior concentração no lodo biológico do que nas cinzas (massa bruta). Isto se dá porque são ânions voláteis e se combinam durante a queima, já o teor sulfatos aumentou nas cinzas (massa bruta) por se tratar de um ânion não volátil. Os sulfatos são encontrados devido ao uso de sulfato de alumínio no processo de tratamento do efluente, enquanto os cloretos, devido ao uso de cloreto de sódio no processo de tingimento. É importante observar a presença destes compostos, pois na combustão, poderão gerar gases corrosivos como $\mathrm{HCl}$ e $\mathrm{HF}$ prejudiciais aos equipamentos e ao meio ambiente.

Em relação ao extrato lixiviado, as concentrações dos parâmetros inorgânicos no lodo biológico e nas cinzas foram abaixo do limite estabelecido pela norma NBR 10.004 (ABNT, 2004). Diferentemente de Avelar (2012), que encontrou valores de $\mathrm{Cr}$ e $\mathrm{Pb}$ acima dos permitidos pela NBR 10.004 (ABNT, 2004), sendo por isso classificado como perigoso. Avelar et al. (2016), por sua vez, classificaram o lodo biológico e os resíduos de algodão como resíduos não inertes. Já as cinzas destes materiais foram classificadas como resíduo perigoso, devendo ser tratado e disposto de forma adequada após a combustão, necessidade não apontada pelos resultados do presente trabalho.

A concentração de Bário no extrato lixiviado das cinzas foi maior do que no extrato lixiviado do lodo. Isso se deve ao fato de o Ba ser um metal pouco volátil, assim, o volume de resíduo diminui, mas a concentração do elemento pouco altera. Fato que também ocorreu no lodo e cinzas da massa bruta, indicando que o aumento da concentração é um reflexo da queima do resíduo.

O teor de $\mathrm{Cr}$ apesar de ter aumentado nas cinzas em relação ao lodo biológico, ambos da massa bruta, como se pode observar na Tabela 2, não aumentou no estrato lixiviado das cinzas em relação ao extrato lixiviado do lodo. Ou seja, a calcinação do lodo aumenta a concentração do elemento em questão, porém, não seu poder de lixiviação. Neste trabalho, todos os parâmetros analisados ficaram abaixo dos limites estabelecidos pela NBR 10.004 (ABNT, 2004). Sendo assim, o lodo e as cinzas foram classificados como resíduos não perigosos, ou seja, Classe II.

A emissão de contaminantes perigosos poderia ser um complicador para uso industrial dos briquetes. Não se pode promover efeitos nocivos ao meio ambiente reutilizando matérias-primas secundárias, ou seja, aumentar a poluição. O foco é a diminuição da contaminação ambiental. Outrora, os resíduos eram depositados em grandes aterros industriais, permanecendo por um longo tempo de vida. Com uso energético reaproveita-se parte dessa energia nas indústrias e aumenta-se o tempo de vida útil dos aterros sanitários.

A queima pode ser uma boa alternativa para a redução do volume de resíduos, contudo, deve-se levar em consideração a geração de novos resíduos, entre eles a geração de cinzas e as emissões atmosféricas. Os impactos da queima do lodo devem ser estudados em trabalhos futuros em testes em caldeiras que já queimam biomassa, pois assim tem-se uma melhor reprodução de todas as varáveis envolvidas.

$\mathrm{Na}$ Figura 1 podem ser observadas amostras dos briquetes dos quatro tratamentos avaliados, $\mathrm{T} 1=100 \%$ de serragem de Pinus; T2 $=33 \%$ de lodo biológico $+67 \%$ de serragem de Pinus; T3 = $66 \%$ de lodo biológico $+34 \%$ de serragem de Pinus; e T4 $=100 \%$ de lodo biológico.

Os briquetes produzidos com 100\% de serragem de Pinus (T1) ficaram maiores que os produzidos somente com lodo biológico (T4), enquanto os briquetes produzidos com a mistura dos dois (T2 e T3) ficaram com tamanho intermediário. Isso ocorreu devido à massa específica inicial do lodo biológico que era maior ao da serragem de Pinus. Os briquetes produzidos ficaram com a altura entre 23 e $28 \mathrm{~mm}$, sendo que o diâmetro não variou, ficando em média em 33 $\mathrm{mm}$.

$\mathrm{Na}$ Tabela 3 podem ser observados os valores médios de perda de massa, massa específica aparente, umidade de equilíbrio higroscópico, carga máxima de ruptura, materiais voláteis, carbono fixo e cinzas dos briquetes em função da temperatura de compactação $\left(90\right.$ e $\left.130 \quad{ }^{\circ} \mathrm{C}\right)$. Essas características são importantes para determinação de cálculos para uso industrial 
dos briquetes. É através desses parâmetros que se pode dimensionar a planta industrial para uso energético.

Houve maior perda de massa com o aumento da proporção de lodo na mistura e, nos tratamentos T3 e T4, com o aumento da temperatura para $130{ }^{\circ} \mathrm{C}$. É possível que a perda de massa ocorreu devido à evaporação de água durante a compactação, sendo que a umidade do lodo (12\%) foi superior à umidade da serragem de pinus (7\%). Para a temperatura de $90{ }^{\circ} \mathrm{C}$ não houve diferença estatística entre os tratamentos, já para a temperatura de $130^{\circ} \mathrm{C}$ o T4 diferiu dos demais tratamentos, apresentando a maior perda de massa. Comparando as duas temperaturas a diferença estatística apareceu apenas no T4, sendo que em $130{ }^{\circ} \mathrm{C}$ a perda de massa foi superior.

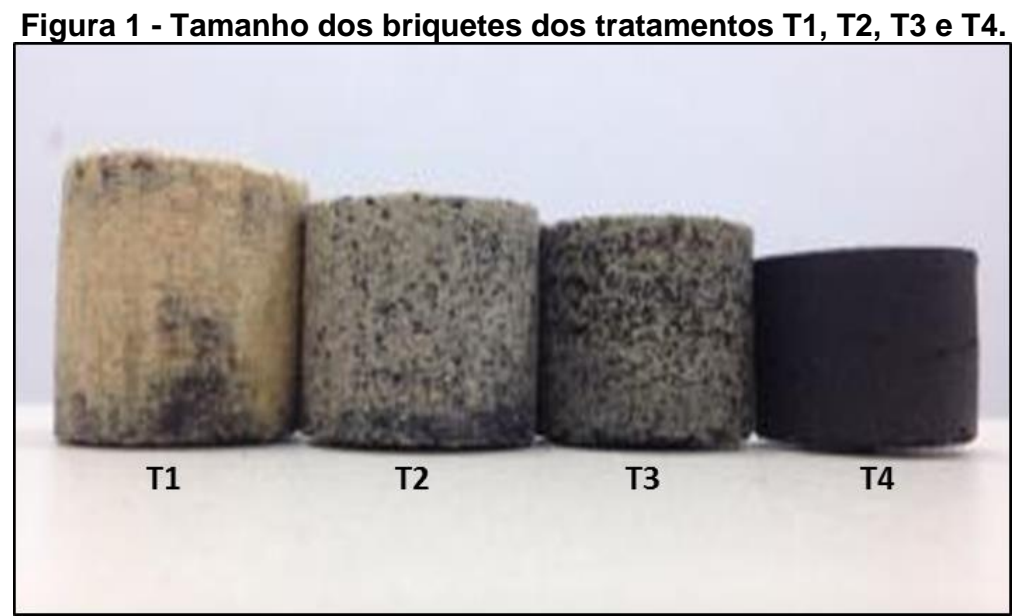

T1 $=0 \%$ de lodo biológico $+100 \%$ de serragem de Pinus; T2 = 33\% de lodo biológico $+67 \%$ de serragem de Pinus; T3 = 66\% de lodo biológico $+34 \%$ de serragem de Pinus; e T4 $=100 \%$ de lodo biológico $+0 \%$ de serragem de Pinus.

Fonte: Autores (2021)

Tabela 3 - PM, ME, UEH, CMR, Mv, Cf e Cz dos briquetes (T1, T2, T3 e T4) em função da temperatura de compactação $\left(90\right.$ e $\left.130^{\circ} \mathrm{C}\right)$.

\begin{tabular}{|c|c|c|c|c|c|}
\hline \multirow{2}{*}{ Parâmetro } & \multirow{2}{*}{ Temperatura $\left({ }^{\circ} \mathrm{C}\right)$} & \multicolumn{4}{|c|}{ Proporção de lodo (\%) } \\
\hline & & $0(\mathrm{~T} 1)$ & 33 (T2) & 66 (T3) & $100(\mathrm{~T} 4)$ \\
\hline $\mathbf{P M}^{*}$ & 90 & $0,81 \mathrm{Aa}^{*}$ & $1,34 \mathrm{Aa}$ & $1,67 \mathrm{Aa}$ & $2,39 A b$ \\
\hline$(\%)$ & 130 & $0,72 \mathrm{Ba}$ & $1,33 \mathrm{Ba}$ & $2,45 \mathrm{Ba}$ & $5,75 \mathrm{Aa}$ \\
\hline$M^{\star}{ }^{\star}$ & 90 & $1,26 \mathrm{Db}^{*}$ & $1,36 \mathrm{Ba}$ & $1,33 \mathrm{Cb}$ & $1,45 \mathrm{Aa}$ \\
\hline$\left(\mathrm{g} . \mathrm{cm}^{-3}\right)$ & 130 & $1,30 \mathrm{Ca}$ & 1,37Ba & $1,36 \mathrm{Ba}$ & $1,44 \mathrm{Aa}$ \\
\hline $\mathrm{CMR}^{\star}$ & 90 & $151,6^{*}$ & 116,8 & 102 & 92,4 \\
\hline$($ kgf.cm²) & 130 & 238,8 & 182,8 & 171,2 & 116,8 \\
\hline UEH $^{*}$ & 90 & $10,29 \mathrm{Ba}^{*}$ & $12,58 \mathrm{Aa}$ & $10,97 \mathrm{Ba}$ & $12,07 \mathrm{Aa}$ \\
\hline$(\%)$ & 130 & $9,56 \mathrm{Cb}$ & $10,46 \mathrm{BCb}$ & $9,98 \mathrm{BCb}$ & 12,55Aa \\
\hline$M v^{* \star}$ & 90 & $83,06 \mathrm{Ab}^{*}$ & $74,53 \mathrm{Ba}$ & $68,22 \mathrm{Ca}$ & $62,27 \mathrm{Da}$ \\
\hline$(\%)$ & 130 & $84,56 \mathrm{Aa}$ & 73,27Ba & $67,24 \mathrm{Ca}$ & $62,71 \mathrm{Da}$ \\
\hline$C f^{\star *}$ & 90 & $16,55 \mathrm{Ca}^{*}$ & $17,95 \mathrm{Ab}$ & $17,05 \mathrm{Ba}$ & $16,34 \mathrm{Ca}$ \\
\hline$(\%)$ & 130 & $15,03 \mathrm{Cb}$ & $19,71 \mathrm{Aa}$ & $18,03 \mathrm{Ba}$ & $16,04 \mathrm{Ca}$ \\
\hline $\mathbf{C z}^{\star \star \star}$ & 90 & $0,39^{*}$ & 7,52 & 14,73 & 21,4 \\
\hline (\%) & 130 & 0,41 & 7,02 & 14,73 & 21,25 \\
\hline
\end{tabular}

PM: perda de massa; ME: massa específica aparente; CMR: carga máxima de ruptura; UEH: umidade de equilíbrio higroscópico; Mv: materiais voláteis; Cf: carbono fixo e $\mathrm{Cz}$ : cinzas. ${ }^{*} \mathrm{~N}=5$; ${ }^{* *} \mathrm{~N}=3$. Médias seguidas de letras diferentes, maiúscula na linha e minúscula na coluna, diferem entre si pelo teste de Tukey $(p \leq 0,05)$. Fonte: Autores (2021) 


\section{REA - Revista de estudos ambientais (Online) v.23, n. 1, p.46-56, jan./jun. 2021}

A massa específica dos briquetes ficou entre 1,26 e $1,45 \mathrm{~g} . \mathrm{cm}^{-3}$, sendo que os briquetes com $100 \%$ lodo (T4) apresentaram a maior massa específica, diferindo estatisticamente dos demais tratamentos. Nesse mesmo tratamento (T4) e no T2 não se obteve diferença estatística entre as temperaturas. Os resultados foram maiores que os encontrados por Avelar (2012), que na confecção de briquetes com mistura de lodo biológico têxtil e resíduo de algodão encontrou valores entre 1,18 e 1,27 g.cm ${ }^{-3}$. Rodrigues (2010) encontrou valores entre 1,10 e $1,50 \mathrm{~g}^{\mathrm{cm}} \mathrm{cm}^{-3}$ para briquetes produzidos com mistura de lodo biológico da indústria de papel/celulose e finos de madeira, similares aos valores encontrados nesse trabalho. Avelar et al. (2016) obtiveram valores médios entre 1,18 e $1,27 \mathrm{~g} \cdot \mathrm{cm}^{-3}$, variando a proporção de lodo e a pressão de compactação dos briquetes. Vale destacar que, quanto maior a massa específica do briquete, mais concentrada encontra-se a energia e, consequentemente, maior potencial energético em determinado volume (FURTADO et al., 2010). Além disto, o aumento da massa específica proporciona maior resistência mecânica aos briquetes, tornando-os menos suscetíveis a avarias consequentes de transporte e quedas (SOUZA, 2014).

Em relação à carga máxima de ruptura observa-se que com o aumento da proporção de lodo, a resistência dos briquetes diminui. Isso pode ser explicado pelo fato de - lodo biológico possuir menos material fibroso do que a serragem de Pinus, o que contribui diretamente na resistência dos briquetes. Analisando 0 efeito da temperatura, verificou-se que os briquetes produzidos com a temperatura de $130{ }^{\circ} \mathrm{C}$ apresentaram maior carga máxima de ruptura. Isso ocorre porque que em temperatura mais alta ocorre maior plastificação da lignina presente na serragem de Pinus. Avelar (2012) encontrou valores médios de $93,00 \mathrm{kgf.cm}^{-2}$ em briquetes de diferentes madeiras produzidos com temperatura de $90{ }^{\circ} \mathrm{C}$, valor próximo ao menor valor de carga máxima de ruptura encontrado nesse trabalho. Vilas Boas (2011) encontrou valores entre 114 e $139 \mathrm{kgf.cm}^{-2}$ em briquetes de diferentes madeiras, mais próximos aos valores da presente pesquisa, porém, ainda não alcançam o valor máximo que foi de $238,8 \mathrm{kgf} . \mathrm{cm}^{-2}$. Vale destacar que este é um importante parâmetro de avaliação dos briquetes, pois influencia a integridade dos mesmos quando submetidos a manuseio e empilhamento (AVELAR et al., 2016).

As médias de umidade de equilíbrio higroscópico ficaram entre 9,56 e 12,58\%. Observou-se que, os briquetes produzidos com maior percentual de lodo apresentaram maiores valores de umidade de equilíbrio higroscópico, sendo que T4 diferiu estatisticamente dos demais tratamentos, exceto de T2 na temperatura de $90{ }^{\circ} \mathrm{C}$. Em relação à temperatura, os briquetes produzidos em temperatura de $130{ }^{\circ} \mathrm{C}$ apresentaram valores de umidade de equilíbrio higroscópico significativamente menores em relação aos produzidos em 90 ${ }^{\circ} \mathrm{C}$, exceto os briquetes de T4 que foram iguais estatisticamente. Tais resultados foram similaridade aos encontrados por Avelar (2012), $11 \%$, que produziu briquetes com mistura de lodo biológico têxtil e resíduo de algodão. Dias Junior, Andrade e Costa Junior (2014) encontraram valores entre 13,27 e $15,26 \%$ para briquetes produzidos com mistura de moinha de carvão e resíduo de bambu. Avelar et al. (2016), misturando lodo biológico têxtil e resíduo de algodão, obtiveram valores médios entre 10,57 e $11,19 \%$, variando o teor de lodo e a pressão de compactação do briquete. Este parâmetro de avaliação apresenta grande importância, pois, quando em baixos teores, facilita o transporte e reduz os custos, já que a quantidade de energia por volume transportado maior. Além disso, confere compacidade aos briquetes, aumentando sua resistência mecânica.

Os briquetes com maior percentual de serragem de Pinus apresentaram valores de material volátil mais altos, sendo que T1 foi significativamente superior aos outros tratamentos. Entre as temperaturas somente constatou-se diferença estatística no T1, onde o material volátil foi maior em $130{ }^{\circ} \mathrm{C}$. Os valores variavam entre 84,56 e $62,27 \%$. Dias Junior, Andrade e Costa Junior (2014) encontraram valores de material volátil na ordem de $81 \%$ em briquetes produzidos com resíduo de bambu. Avelar et al. (2016) chegaram a valores médios entre 76,89 e $78,85 \%$ misturando lodo biológico têxtil e resíduo de algodão e variando o teor de lodo e a pressão de compactação. Nunes et al. (2018) obtiveram $80,26 \%$ para briquetes produzidos com resíduos têxteis.

O carbono fixo foi mais alto nos briquetes produzidos com mistura de serragem de Pinus e lodo biológico (T2 e T3), sendo T2 significativamente superior aos demais tratamentos. Diferença estatística 
entre as temperaturas apareceu nos tratamentos $\mathrm{T} 1$ e T2, porém para a temperatura não se observou um padrão de comportamento. Avelar (2012) encontrou valores entre 8,71 e $10,96 \%$, menores do que os encontrados nesse trabalho (15,03 a $19,71 \%$ ). Nunes et al. (2018) obtiveram $13,86 \%$ analisando briquetes com resíduos têxteis. Avelar et al. (2016) chegaram a valores entre 8,35 e $10,96 \%$ variando a proporção de lodo e a pressão de compactação. Os autores destacaram que este parâmetro pode fornecer uma medida da facilidade de o material entrar em combustão. Os valores obtidos pelo presente trabalho mostraram-se superiores aos encontrados nos estudos analisados, fato a ser destacado, uma vez que este parâmetro representa a energia química armazenada no material.

Os valores de cinzas variaram entre $0,39 \%$ para briquetes de serragem de pinus (T1) e 21,4\% para briquetes de lodo biológico puro (T4), apresentando correlação linear
$\left(R^{2}=0,9992\right)$ de acordo com a adição de lodo à serragem de pinus. Dias Junior, Andrade $\mathrm{e}$ Costa Junior (2014) encontraram valores um pouco superiores, entre 2,60 e $27 \%$. As diferentes temperaturas não apresentaram efeito sobre as cinzas. Avelar et al. (2016) obtiveram valores médios com variação menor, entre 12,15 e 13,32\%. Nunes et al. (2018) chegaram ao valor de 0,52\% para briquetes com resíduos têxteis.

Os valores de poder calorífico superior encontrados, entre 17,09 e 19,78 MJ.kg-1 (Tabela 4), são compatíveis aos encontrados em briquetes produzidos com outros resíduos de madeira. Rodrigues (2010) encontrou valores médios entre 15 a 19 MJ.kg-1 ${ }^{-1}$ enquanto Gonçalves, Sartori e Leão (2009) encontraram valores médios entre 19

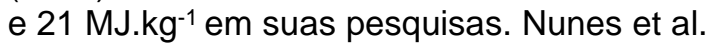
(2018) obtiveram 16,80 MJ.kg-1. Este parâmetro mostra-se importante uma vez que indica a qualidade do briquete como fonte de energia (AVELAR et al., 2016).

Tabela 4 - PCS dos briquetes (T1, T2, T3 e T4) em função da temperatura de compactação $\left(90\right.$ e $\left.130{ }^{\circ} \mathrm{C}\right)$

\begin{tabular}{cccccc}
\hline \multirow{2}{*}{ Parâmetro } & \multirow{2}{*}{ Temperatura $^{\circ} \mathbf{C}$} & \multicolumn{4}{c}{ Proporção de lodo \% } \\
\cline { 3 - 6 } & & $\mathbf{0}(\mathbf{T 1})$ & $\mathbf{3 3}(\mathbf{T 2})$ & $\mathbf{6 6}(\mathrm{T3})$ & $\mathbf{1 0 0}$ (T4) \\
\hline PCS & $\mathbf{9 0}$ & 19,72 & 18,86 & 18,06 & 17,09 \\
(MJ.kg $\left.^{-1}\right)$ & $\mathbf{1 3 0}$ & 19,78 & 18,91 & 18,01 & 17,23 \\
\hline
\end{tabular}

PCS: poder calorífico superior.

Fonte: Autores (2021)

Contudo, pode-se afirmar que a proporção de mistura entre lodo biológico e serragem de Pinus (T1, T2, T3 e T4) não influencia na geração de energia. Isso porque, algumas variações significativas observadas nos parâmetros da Tabela 3 não foram grandes o suficiente para influenciar de forma significativa os valores de poder calorífico superior entre os tratamentos (Tabela 4). Entretanto, é preciso observar qual dessas proporções permite que os briquetes sejam trabalháveis na indústria, uma vez que sua estrutura e manutenção de forma são importantes.

\section{Conclusões}

O lodo físico-químico não apresentou características desejáveis para aproveitamento energético, pois o baixo poder calorífico superior (PCS) (<4 MJ.kg-1) e alta umidade não são viáveis para combustão.
O lodo biológico apresentou características desejáveis para uso em conjunto com a biomassa vegetal para geração de energia, pois seu poder calorífico superior (> 17 MJ.kg-1) é próximo ao das biomassas atualmente usadas na geração de energia.

Os valores dos elementos químicos determinados no extrato lixiviado do lodo biológico e das cinzas ficaram abaixo dos limites estabelecidos pela NBR 10.004 (ABNT, 2004) e, portanto, os resíduos não foram classificados como perigosos.

A produção de briquetes com a mistura de lodo biológico e serragem de Pinus mostrou-se uma alternativa para 0 aproveitamento energético.

Os briquetes produzidos apresentaram resultados favoráveis ao uso em caldeiras, com resultados melhores para os briquetes com $33 \%$ de lodo, que apresentaram melhor resistência e poder calorífico superior (18,89 MJ.kg-1).

Não houve interação significativa entre a proporção de lodo e a temperatura de 
compactação para o poder calorífico superior, apenas efeito quanto à proporção de mistura. O aumento da proporção de lodo biológico na mistura diminui o poder calorífico superior, ou seja, o maior poder calorífico superior foi apresentado pelo T1 (19,78 MJ.kg-1).

\title{
5 Textile Sludge Briquettes for Thermal Power Generation
}

\begin{abstract}
The development of waste recovery techniques is a necessity to reduce the raw materials use and environmental degradation. The use of textile sludge in the production of briquettes for energy generation is an alternative. Thus, briquettes with four proportions of biological sludge or physical-chemical sludge $(0,33,66$ and $100 \%$ ) mixed with Pinus sawdust were produced at two temperatures $\left(90\right.$ and $130^{\circ} \mathrm{C}$ ). The biological sludge

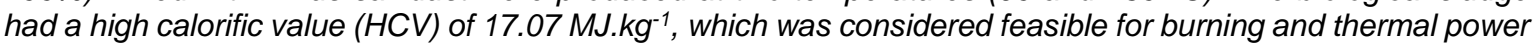
generation, whereas the physical-chemical sludge presented HCV of $3.4 \mathrm{MJ}^{\mathrm{kg}}{ }^{-1}$, unviable for this purpose. The briquettes produced with biological sludge presented favorable results for use in boilers, and those with $33 \%$ of sludge presented higher resistance $\left(149.8 \mathrm{kgf.cm}-{ }^{2}\right)$ and $\mathrm{HCV}\left(18.89 \mathrm{MJ} . \mathrm{kg}^{-1}\right)$. The ashes resulting from burning briquettes were below the limit set by the NBR 10004 (ABNT, 2004), for the inorganic parameters.
\end{abstract}

Keywords: Textile sludge; waste recovery; thermal energy.

\section{Referências}

ABNT - ASSOCIAÇÃO BRASILEIRA DE NORMAS TÉCNICAS. NBR 8.633. Carvão vegetal: determinação do poder calorífico: método de ensaio. Rio de Janeiro - RJ: ABNT, 1984, 13 p.

ABNT - ASSOCIAÇÃO BRASILEIRA DE NORMAS TÉCNICAS. NBR 8.112. Carvão vegetal: análise imediata. Rio de Janeiro - RJ: ABNT, 1986, $6 \mathrm{p}$.

ABNT - ASSOCIAÇÃO BRASILEIRA DE NORMAS TÉCNICAS. NBR 7.190. Projeto de estruturas de madeira. Rio de Janeiro - RJ: ABNT, 1997, 107 p.

ABNT - ASSOCIAÇÃO BRASILEIRA DE NORMAS TÉCNICAS. NBR 10.004. Resíduos Sólidos: Classificação. 2. ed. Rio de Janeiro - RJ: ABNT, 2004, $71 \mathrm{p}$.

ABNT - ASSOCIAÇÃO BRASILEIRA DE NORMAS TÉCNICAS. NBR 10.005. Resíduos Sólidos: Obtenção do extrato lixiviado. 2. ed. Rio de Janeiro - RJ: ABNT, 2004, 16 p.

ABNT - ASSOCIAÇÃO BRASILEIRA DE NORMAS TÉCNICAS. NBR 10.007. Resíduos Sólidos: Coleta de resíduos. 2. ed. Rio de Janeiro - RJ: ABNT, 2004, $21 \mathrm{p}$.

APHA - American Public Health Association. Standard Methods for the examination of Water and Wasterwater. 21. Ed., American Public Health Association, American Water Works Association and Water Environment Federation. Washintong D.C. 2005.

ARAÚJO, A. S. F.; MONTEIRO, R. T. R.; CARDOSO, P. F. Composto de lodo têxtil em plântulas de soja e trigo. Pesquisa Agropecuária Brasileira, v. 40, p. 549-554, 2005.

AVELAR, N. V. Potencial dos resíduos sólidos da indústria têxtil para fins energéticos. 2012. 71 f. Dissertação (Mestrado em Engenharia Civil) Universidade Federal de Viçosa, Viçosa, 2012.

AVELAR, N. V. R.; CARNEIRO, A. A. P.; SILVA, A. C. O.; MUDABU, C. Evaluation of briquettes made from textile industry solid waste. Renewable Energy, V. 91, p. 417-424, 2016.

AVELAR, N. R.; REZENDE, A. A. P.; CARNEIRO, A. C. O.; SILVA, C. M. Avaliação das características de densidade aparente, carga máxima de ruptura e umidade de equilíbrio higroscópico de briquetes produzidos a partir de resíduos da indústria têxtil. In: CONGRESSO BRASILEIRO DE ENGENHARIA SANITÁRIA E AMBIENTAL, 27, 2013, Goiânia. Anais... Goiânia, 2013.

BASTIAN, E. Y. O; ROCCO, J. L. S. Guia técnico ambiental da indústria têxtil - série $P+L$. São Paulo - SP: CETESB, SINDITÊXTIL, 2009. 85 p.

BORGES, F.; SELLIN, N.; MEDEIROS, S. H. W. Caracterização e avaliação de lodos de efluentes sanitários e industrial como biomassa na geração de energia. Ciência \& Engenharia, v. 17 p. 27-32, 2008.

DIAS JUNIOR, A. F.; ANDRADE, A. M.; COSTA JUNIOR, D. S.; Caracterização de briquetes produzidos com resíduos agroflorestais. Revista Pesquisa Florestal Brasileira, v. 34, n. 79, p. 225234, 2014.

EPA - United States Environmental Protection Agency. EPA 3051A. Microwave assisted acid 
digestion of sediments, sludges, soils, and oils. 2007, 30 p.

EPA - United States Environmental Protection Agency. EPA 9056A. Determination of inorganic anions by ion chromatography. 2007, 19 p.

FEAM - Fundação Estadual do Meio Ambiente. Aproveitamento energético de resíduos sólidos urbanos: guia de orientação para governos municipais de Minas Gerais. Belo Horizonte: FEAM, 2012. 163 p.

FELDER, C.; AZZOLINI, J. C. Estudo de viabilidade de queima de resíduos originários da indústria de laticínio. Revista Unoesc e Ciência ACET, v. 4, n. 1, p. 71-84, 2013.

FURTADO, T. S.; VALIN, M.; BRAND, M.; BELLOTE, A. F. J. Variáveis do processo de briquetagem e qualidade de briquetes de biomassa florestal. Pesquisa Florestal Brasileira, v.30, n.62, p.101-106, 2010.

GONÇALVES, J. E.; SARTORI, M. M. P.; LEAO A. $L$. Energia de briquetes produzidos com rejeitos de resíduos sólidos urbanos e madeira eucaliptos grandis. Revista Brasileira de Engenharia Agrícola e Ambiental, v. 13, n. 5, p. 657-661, 2009.

LIMA, E. A.; ABDALA, E. M.; WENZEL, A. A. Influência da umidade no poder calorífico superior da madeira. Colombo - PR: Embrapa Florestas, 2008. 3 p.

MAGDZIARZ, A., Wilk, M. Thermal characteristics of the combustion process of biomass and sewage sludge. Journal of Thermal Analysis and Calorimetry, v. 114, p. 519-529, 2013.

MORAIS, S. A. L. D.; NASCIMENTE, E. A. D.; MELO, D. C. D.; Análise da madeira de pinus ocarpa parte I - estudo dos constituintes macromoleculares e extrativos voláteis. Revista Árvore, v. 29 n. 3 p. 461-470, 2005.

NUNES, L. J. R.; GODINA, R.; MATIAS, J. C. O.; CATALÃO, J. P. S. Economic and environmental benefits of using textile waste for the production of thermal energy. Journal of Cleaner Production, v. 171, n. 10 , p. 1353-1360, 2018.

PASQUINI, N. C. Uso potencial como fonte de energia de lodo proveniente de esgoto doméstico e industrial. Revista Ciências Exatas e Naturais, v. 16, n. 1, p. 35-57, 2014.

PSOMOPOULOS, C. S.; BOURKA, A.; THEMELIS, N. J.; Waste to energy: A reviev of the status and benefits in USA. Waste Management, v. 29, n. 5, p. 1718-1724, 2009.

ROSA, A. P.; CHERNICHARO, C. A. L.; MELO, G. C. B. Contribuição para o aproveitamento energético do lodo de ETEs em processos térmicos. Revista DAE, p. 55-62, 2015.

VIEIRA, G. E. G.; PEDROZA, M. M.; SOUZA, J. F.; PEDROZA, C. M. O processo de pirólise como alternativa para o aproveitamento do potencial energético de lodo de esgoto - uma revisão. Revista Liberato, v. 12, n. 17, p. 01-106, 2011.

VIKOVÁ, M.; PERIYASAMY, A. P.; VIK, M.; UJHELYIOVÁ, A. Effect of drawing ratio on difference in optical density and mechanical properties of mass colored photochromic polypropylene filaments. Journal of the Textile Institute, v. 108, p. 1365-1370, 2017.

VILAS BOAS, M. A. Efeito do tratamento térmico da madeira para a produção de briquetes. 2011. 65 f. Dissertação (Mestrado em Ciência Florestal) Universidade Federal de Viçosa, Viçosa - MG, 2011.

RENOSAM. The most efficient waste management system in Europe: Waste-toenergy in Denmark. Denmark: Ramboll. 2006, 23 p.

RODRIGUES, V. A. J.; Valorização energética do lodo biológico da indústria de polpa celulósica através da briquetagem. 2010. 117 f. Dissertação (mestrado) - Universidade Federal de Viçosa, Viçosa - MG, 2010.

SOUZA, F. Avaliação da qualidade de briquetes produzidos com seis biomassas agroflorestais por métodos não destrutivos. 2014. 142 p. Tese (doutorado) - Universidade de Brasília, Brasília DF, 2014.

WANG, J. J.; YANG, K.; XU, Z. L.; FU, C. Energy and exergy analyses of an integrated CCHP system with biomass air gasification. Applied Energy, v. 142, n. 15, p. 317-327, 2015.

WANG, X.; DENG, S.; TAN, H.; ADEOSUN, A.; VUJANOVIC, M.; YANG, F.; DUIC, N. Synergetic effect of sewage sludge and biomass co-pyrolysis: A combined study in thermogravimetric analyzer and a fixed bed reactor. Energy Conversion and Management, v. 118, n. 15, p. 399-405, 2016.

XIE, C.; LIU, J.; XIE, W.; KUO, J.; LU, X.; ZHANG, X.; HE, Y.; SUN, J.; CHANG, K.; XIE, W.; LIU, C.; SUN, S.; BUYUKADA, M.; EVRENDILEK, F. Quantifying thermal decomposition regimes of textile dyeing sludge, pomelo peel, and their blends. Renewable Energy, v. 122, p. 55-64, 2018.

STOLARSKI, M. J.; SZCZUKOWSKI, S.; TWORKOWSKI, J.; KRZY_ZANIAK, M.; GULCZY_NSKI, P.; MLECZEK, $\bar{M}$. Comparison of quality and production cost of briquettes made from agricultural and forest origin biomass. Renewable Energy. v. 57, p. 20-26, 2013. 